\title{
TAT-mediated intracellular delivery of purine nucleoside phosphorylase corrects its deficiency in mice
}

\author{
Ana Toro' ${ }^{1}$ and Eyal Grunebaum¹,2 \\ ${ }^{1}$ Infection, Immunity, Injury and Repair Program, Research Institute, and \\ 2Division of Allergy and Clinical Immunology, Hospital for Sick Children and University of Toronto, Toronto, Ontario, Canada.
}

\begin{abstract}
Defects in purine nucleoside phosphorylase (PNP) enzyme activity result in abnormal nucleoside homeostasis, severe $\mathrm{T}$ cell immunodeficiency, neurological dysfunction, and early death. Protein transduction domain (PTD) can transfer molecules into cells and may help restore PNP activity in cases of PNP deficiency. However, long-term use of PTD to replace enzymes in animal models or patients has not previously been described. We fused human PNP to the HIV-TAT PTD and found that the fusion with TAT changed the retention and distribution of PNP in PNP-deficient mice. TAT induced rapid intracellular delivery of PNP into tissues, including the brain, prevented urinary excretion of PNP, and protected PNP from neutralizing antibodies, resulting in significant extension of the enzyme's biological activity in vivo. Frequent TAT-PNP injections in PNP-deficient mice corrected the metabolic disorder and immune defects with no apparent toxicity. TAT-PNP remained effective over 24 weeks of treatment, resulting in continued improvement in immune function and extended survival. Our data demonstrate that TAT changes the properties of PNP in vivo and that long-term intracellular delivery of PNP by TAT corrects PNP deficiency in mice. We provide evidence to promote further use of PTD to treat diseases that require repeated intracellular enzyme or protein delivery.
\end{abstract}

\section{Introduction}

Purine nucleoside phosphorylase (PNP) is a ubiquitous enzyme essential for purine degradation and salvage (Figure 1A). Defective PNP activity results in nucleoside imbalance that leads to severe $\mathrm{T}$ cell immunodeficiency (1). Mutations that interfere with the production and function of PNP prevent the degradation of purine nucleosides (deoxy)inosine and (deoxy)guanosine to the corresponding purine bases and ribose 1-phosphate (2). Accumulation of deoxyguanosine in the mitochondria of thymocytes, which is phosphorylated to deoxy-GTP, interferes with DNA synthesis and repair in these cells, particularly double-positive $\left(\mathrm{CD} 4^{+} \mathrm{CD} 8^{+}\right)$ thymocytes, culminating in their increased apoptosis (3). Small hypoplastic thymus, reduced $\mathrm{T}$ lymphocytes in peripheral blood, abnormal response of $\mathrm{T}$ lymphocytes to stimulation, and enlarged spleen are found in most PNP-deficient patients (4). These immune abnormalities contribute to the death of PNP-deficient patients in the first years of life from infections, autoimmunity, or malignancy $(4,5)$. Some patients also suffer from neurological defects, possibly reflecting the importance of purine homeostasis for brain development, as demonstrated in other diseases with abnormal purine metabolism (Figure 1A) such as hypoxanthineguanine phosphoribosyltransferase deficiency (Lesch-Nyhan syndrome) and adenosine deaminase (ADA) deficiency $(6,7)$.

For most PNP-deficient patients there is no effective treatment. In contrast to other enzyme defects (such as ADA deficiency), enzyme replacement therapy is currently not available for PNP-deficient patients (8). Furthermore, PNP is an intracellular

Nonstandard abbreviations used: ADA, adenosine deaminase; ALT, alanine aminotransferase; AST, aspartate aminotransferase; PNP, purine nucleoside phosphorylase; PTD, protein transduction domain; TAT, trans-activator of transcription.

Conflict of interest: The authors have declared that no conflict of interest exists. Citation for this article: J. Clin. Invest. 116:2717-2726 (2006). doi:10.1172/JCI25052. enzyme; therefore an ideal enzyme replacement strategy would deliver PNP into the cells. Additional evidence indicating that intracellular PNP delivery may be superior to other forms of therapy in PNP-deficient patients is derived from the disappointing results of hematopoietic stem cell transplantations or frequent transfusions with allogeneic red blood cells, which are rich in PNP (9). These procedures remove toxic purine metabolites; however, the recovery of the immune system is only temporary (10). Moreover, neurological abnormalities often persist after stem cell transplantations $(11,12)$. Thus, treatments that allow penetration of PNP into the brain may be advantageous for PNP-deficient patients. Recently, a murine model of PNP deficiency was generated, in which the catalytic domain of the PNP gene was disrupted (3). These $\mathrm{PNP}^{-/-}$mice display metabolic, immune, and phenotypic abnormalities similar to those found in PNP-deficient patients (1), suggesting that $\mathrm{PNP}^{-/-}$mice, which provide a null background, may also be helpful for evaluating treatments of PNP deficiency, including intracellular PNP delivery.

Protein transduction domains (PTDs) are a group of peptides that can cross biological membranes in a receptor-independent manner (13). In 1988, 2 groups found that the trans-activator of transcription (TAT) protein from HIV could readily enter cells and initiate transcription $(14,15)$. TAT is essential for the activation and expression of HIV genes and may also help the virus escape from immune surveillance (16). However, the importance of the PTD for the function of the TAT protein or for HIV virulence is still not clear. Subsequently, other PTDs were discovered $(17,18)$, although the precise mechanisms of membrane transduction by PTD are still under investigation $(19,20)$. Since the discovery that only 11 amino acids of TAT are required for transduction and the description of a "user-friendly" method to produce TAT fusion proteins, the use of TAT PTD has increased significantly $(21,22)$. In vitro, PTD can deliver various cargo mol- 


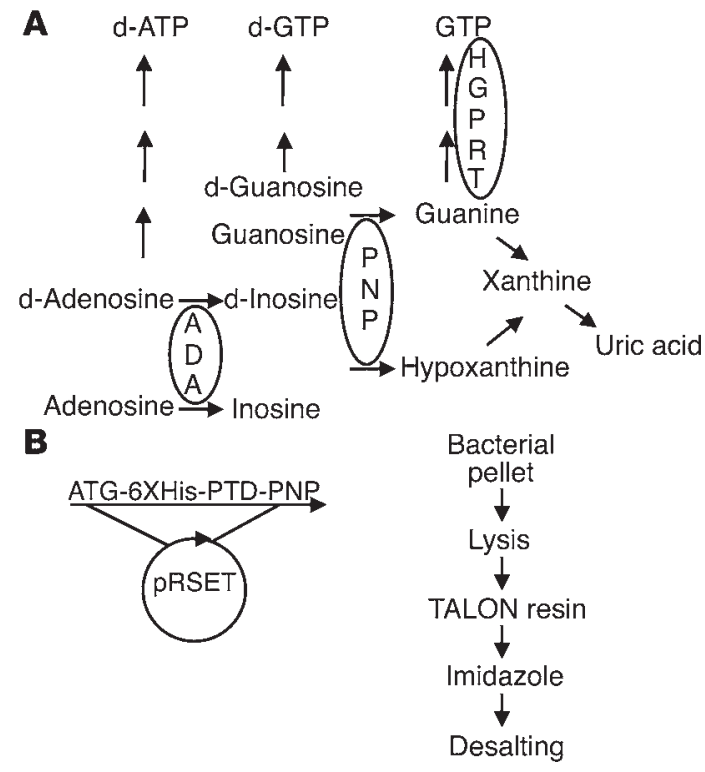

ecules into practically all cells (23-27), although few researchers still argue that artifacts may account for some of the effects of TAT $(28,29)$. Some have also harnessed PTD to deliver small molecules (14-21 amino acids) for relatively short periods in vivo (30-32). Yet while TAT enzyme replacement in vitro has been successfully demonstrated in many previous publications (23-27), to our knowledge such therapy has never been tested in animal models, thus its true potential as a method to correct enzyme deficiencies in patients is not yet known. Some of the potential limitations of prolonged TAT-enzyme treatment include toxicity induced by TAT fusion and difficulties in producing adequate amounts of fusion proteins to achieve physiological benefit (33). Additionally, full-length TAT has been shown previously to induce an immune response $(34,35)$; thus fusion with TAT could also increase the immunogenicity of proteins. Indeed, neutralizing antibodies have limited several enzyme and protein replacement therapies such as ADA, insulin, or factor VIII $(36,37)$.

We generated PNP fused to TAT (TAT-PNP) and demonstrated in $\mathrm{PNP}^{-/-}$mice that TAT induced rapid and efficient delivery of active PNP into many tissues, including the brain. We also showed that TAT-PNP was not toxic to the mice and that intracellular transduction protected TAT-PNP from neutralizing antibodies. Importantly, TAT-PNP administration over an extended period (24 weeks) corrected the metabolic abnormalities and immunodeficiency and prevented the early death of $\mathrm{PNP}^{-/-}$mice.

\section{Results}

TAT-PNP transduction in PNP $\mathrm{P}^{-/-}$mice. To study PNP transduction by PTD, we generated TAT-PNP fusion protein by replacing the ATG of the human PNP cDNA with the coding sequence for the 11 amino acids of the TAT PTD (38). PNP without the TAT domain (nonfused PNP) was similarly produced. Proteins were expressed in E. coli and purified. Both TAT-PNP and nonfused PNP had similar enzyme activity, as assessed by their ability to convert labeled inosine into hypoxanthine. On average 1 unit of activity was obtained from $10.2 \mu \mathrm{g}$ of recombinant protein. TAT delivered PNP into human PNP-deficient cells, resulting in increased PNP activity within the cells for 96 hours (data not shown). We

\section{Figure 1}

Role of PNP in purine metabolism and the production of TAT-PNP. (A) PNP phosphorylates deoxyguanosine (d-Guanosine) and guanosine to guanine and deoxyinosine and inosine to hypoxanthine, both of which can be further metabolized to uric acid. PNP deficiency results in accumulation of PNP substrates and reduced products such as guanine and uric acid. Defects in purine metabolism enzymes such as PNP or ADA cause severe immune defects. Mutations in hypoxanthine-guanine phosphoribosyltransferase (HGPRT) are associated with neurological abnormalities, similar to PNP and ADA deficiencies. (B) The coding sequence of the 11-amino acid TAT PTD (YGRKKRRQRRR) flanked by glycine residues was inserted by PCR upstream of human PNP (without the ATG). TAT-PNP was inserted into pRSET vector with an N-terminal Histidine tag (6XHis) and expressed in E. coli BL21(DE3). The bacterial pellet was lysed, applied to a resin column, washed, eluted with imidazole, and desalted.

employed multiple strategies to exclude the possibility that our techniques damaged cell membranes and allowed artificial penetration of the recombinant proteins $(28,29)$. The ability of TAT to transduce PNP in vivo was evaluated using the unique features of $\mathrm{PNP}^{-/-}$mice (3). The disruption of the catalytic domain of the murine PNP gene prevents the production of $\mathrm{PNP}$ in $\mathrm{PNP}^{-/-}$mice; therefore, PNP detected following treatment is of exogenous origin. To understand the distribution of TAT-PNP PTD in vivo, $\mathrm{PNP}^{-/-}$mice were injected with $2.5 \mathrm{U} / \mathrm{g}$ body wt of TAT-PNP or nonfused PNP. Lysed whole blood, tissues, and urine samples were assessed for PNP activity and presence. PNP activity was analyzed by a sensitive enzyme assay, which enables small changes in PNP to be quantified (3). The internalization of the proteins was visualized using confocal microscopy, which allows sectioning through the cells, with anti-human PNP antibodies that we generated.

Fifteen minutes after administration of TAT-PNP and nonfused PNP, the enzyme activity in whole blood of treated mice increased to $44.0 \pm 2.6 \mathrm{nmol} / \mathrm{min} / \mathrm{mg}$ protein and $46.1 \pm 2.1 \mathrm{nmol} / \mathrm{min} / \mathrm{mg}$ protein, respectively, both more than $80 \%$ of the activity found in blood samples from normal control littermates $(53 \pm 1.5 \mathrm{nmol} / \mathrm{min} / \mathrm{mg}$ protein). However, within 30 minutes of the injections, significant differences between TAT-PNP and nonfused PNP were recorded (Figure 2A). Enzyme activity in the blood of mice that received nonfused PNP declined rapidly; 2 hours after injection, it was $6.1 \pm 2.9 \mathrm{nmol} / \mathrm{min} / \mathrm{mg}$ protein $(11 \% \pm 5 \%$ of control). Moreover, 4 hours after injection of nonfused PNP, enzyme activity was undetectable in the blood. In contrast, while some decrease in enzyme activity was also evident 30 minutes after TAT-PNP administration, it remained significantly elevated even after 8 hours $(7.2 \pm 3.1 \mathrm{nmol} / \mathrm{min} / \mathrm{mg} ; 14 \% \pm 6 \%$ of control). Furthermore, at 4 and even 8 hours after TAT-PNP injections, enzyme activity in various organs such as the spleen, kidney, liver, brain, thymus, and heart were still significantly increased (Figure 2B). For example, enzyme activity in the kidneys of $\mathrm{PNP}^{-/-}$mice 8 hours after TAT-PNP injections was $41.3 \pm 12.4 \mathrm{nmol} / \mathrm{min} / \mathrm{mg}$ protein, compared with $96.2 \pm 6.1 \mathrm{nmol} / \mathrm{min} / \mathrm{mg}$ protein in the kidneys of normal control littermates. In marked contrast, 4 hours after injection of nonfused PNP, no enzyme activity was detected in any organ.

Fluorescence images obtained with anti-PNP antibodies by confocal microscopy confirmed that 4 hours after injection, TAT delivered PNP into the cells of the liver and spleen (Figure 2C) as well as the kidney, heart, thymus, and brain (data not shown). In contrast, fluorescence was not observed in the organs of mice following nonfused PNP administration (Figure 2C), which also 
A

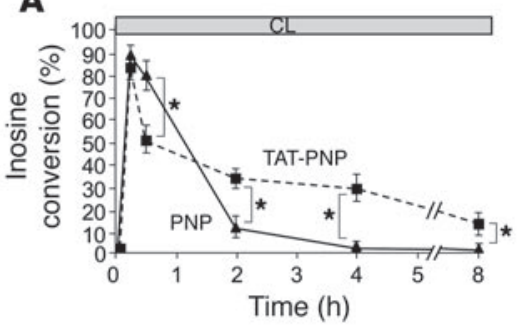

C

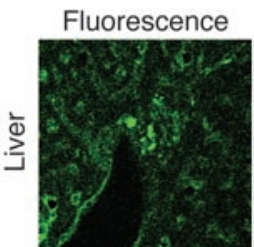

TAT-PNP

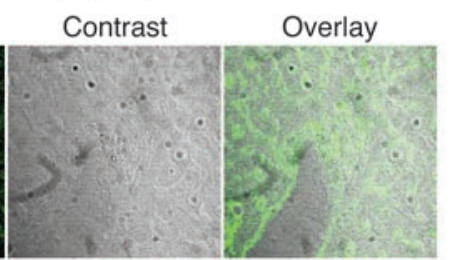

Contrast

Overlay

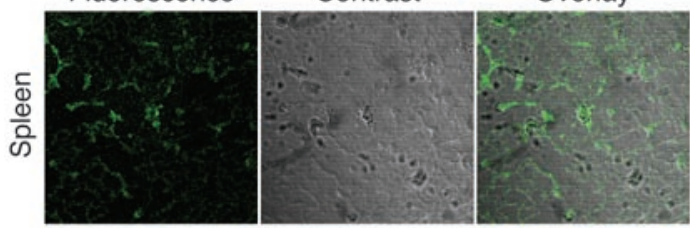

B

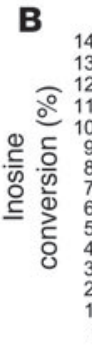

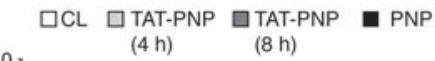
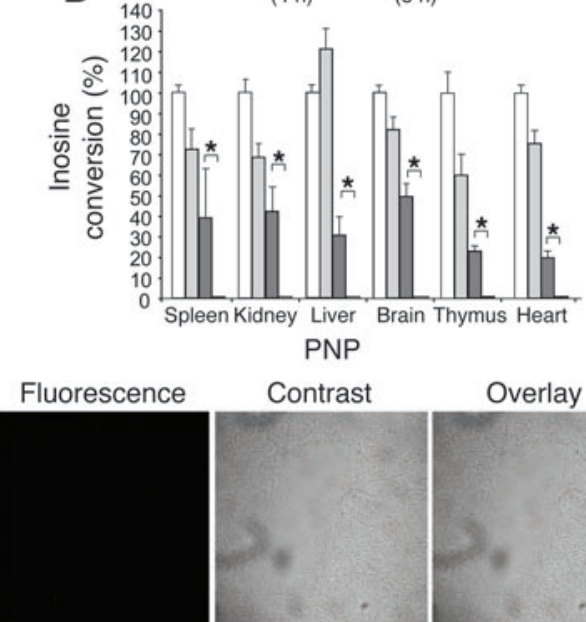

Fluorescence
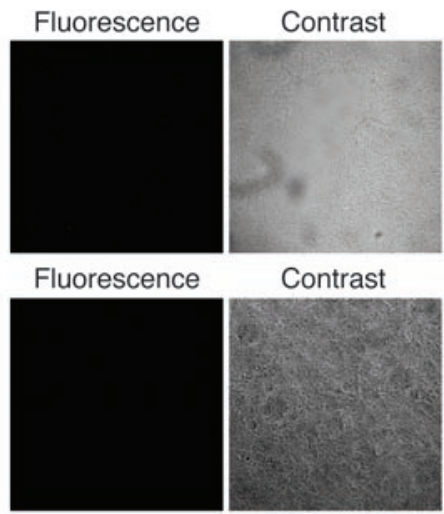

Contrast

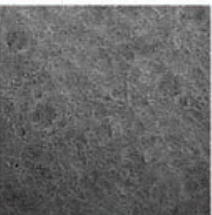

Overlay

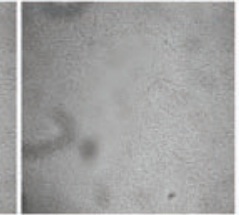

Overlay
D
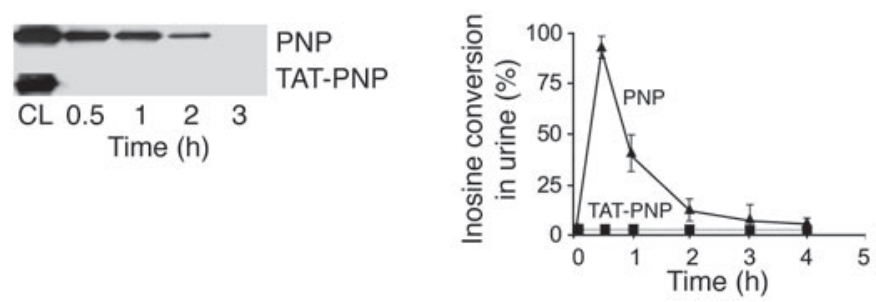

Figure 2

Transduction of TAT-PNP in PNP ${ }^{-1-}$ mice. TAT delivered active PNP into the tissues and prevented urinary excretion of the fused protein. PNP ${ }^{-1}$ mice (5-8 per group) were injected i.p. with $2.5 \mathrm{U} / \mathrm{g}$ body wt of TAT-PNP or PNP. Whole blood, tissue samples, and urine obtained from $\mathrm{PNP}^{-1-}$ mice after injections were tested for the proteins' presence and function after removal of membrane-bound proteins by washing with acidic buffer. PNP activity was determined by ${ }^{14} \mathrm{C}$-inosine conversion and is compared with PNP activity in samples obtained from normal control littermates (CL). (A) PNP activity in whole blood samples at the indicated time points after injections. (B) PNP activity in cell suspensions of various organs 4 and 8 hours after injections. (C) Detection of TAT-PNP intracellular transduction by confocal fluorescence microscopy in tissues 4 hours after injections. Sections were stained with rabbit anti-human PNP antibodies and secondary donkey Alexa 488-conjugated anti-rabbit antibody. Original magnification, $\times 200$. (D) Urine samples were evaluated for the presence of recombinant proteins compared with $0.5 \mu \mathrm{g}$ PNP. Western blot analysis with rabbit anti-PNP antibody and analysis of inosine conversion at the indicated time points after injections demonstrate that PNP, but not TAT-PNP, was excreted into the urine. Results (mean \pm SD) are representative of 3 independent experiments. ${ }^{*} P<0.05$.

xanthine, which may then be degraded into xanthine and eventually cleared as uric acid (Figure 1A); therefore, $\mathrm{PNP}^{-/-}$mice do not produce uric acid. We took advantage of this pathway and monitored PNP activity by examining uric acid production, which was easily measured because uric acid is secreted into the urine. Uric acid was quantified by a colorimetric reaction, which is directly proportional to uric acid concentrations. Threeweek-old $\mathrm{PNP}^{-/-}$mice were injected i.p. with TAT-PNP, nonfused PNP, or a similar volume of PBS. Urine was collected 24 hours later. A significant increase in uric acid concentration $(75 \pm 2.5 \mu \mathrm{mol} / 1)$ was observed in urine samples from $\mathrm{PNP}^{-/-}$ mice treated with TATPNP (0.5 U/g body $w \mathrm{t})$ over samples from mice treated with fused PNP, PBS, or reduced amounts of TAT-PNP, which showed no uric acid production. The presence of uric acid after TAT-PNP injections, as described above, which was greater than $50 \%$ of the levels recorded in normal control littermates (120-160 $\mu \mathrm{mol} / 1)$,

confirmed that the intracellular detection of TAT-PNP was not an experimental artifact. We hypothesized that some of the difference between TAT-PNP and nonfused PNP could reflect elimination of nonfused PNP into the urine. Indeed, after treatment with nonfused PNP (in parallel to the decrease of enzyme activity in the blood), examination of urine samples by Western blot analysis with anti-PNP antibodies and by enzymatic assay revealed that nonfused PNP, but not TAT-PNP, was excreted into the urine (Figure $2 \mathrm{D}$ ). In conclusion, our studies demonstrate that TAT changes the in vivo distribution of PNP by transducing the enzyme into the cells and by preventing its rapid elimination into the urine.

TAT-PNP treatment restores uric acid production in $\mathrm{PNP}^{-1-}$ mice. PNP is essential for the metabolism of nucleosides into hypo- confirmed that TAT-PNP had a significant biological effect on purine metabolism in $\mathrm{PNP}^{-/-}$mice. Furthermore, it suggested that injections of $0.5 \mathrm{U} / \mathrm{g}$ body wt TAT-PNP twice weekly may be adequate for prolonged treatment, which was also similar to a regimen previously used for treating ADA-deficient mice (39).

TAT-PNP treatment is not associated with adverse effects. To our knowledge, there are no reports relating administration of molecules fused to TAT with adverse effects, yet to confirm its safety we performed a dose-toxicity evaluation. $\mathrm{PNP}^{-/-}$and normal control littermates were injected with increasing amounts of TAT-PNP (1, 2 , 4, or $8 \mathrm{U} / \mathrm{g}$ body wt/wk; 5-6 mice per group) over a 4-week period. Liver, kidney and hematological indexes were determined and compared with those of normal control littermates injected with 
A

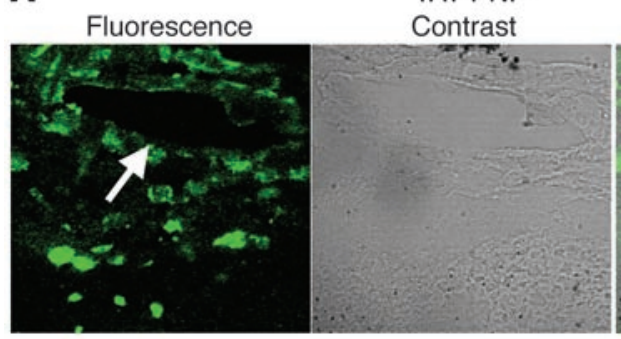

PNP

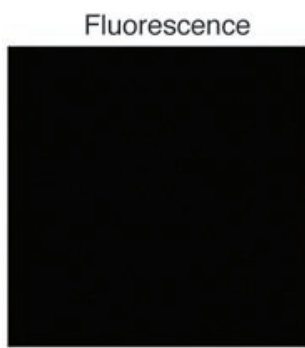

B Alexa 488
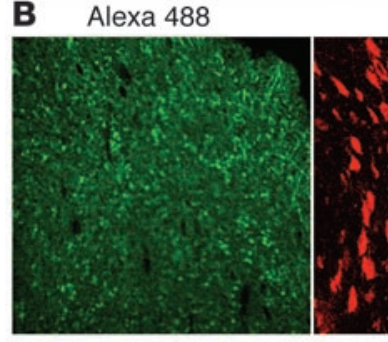

Rhodamine
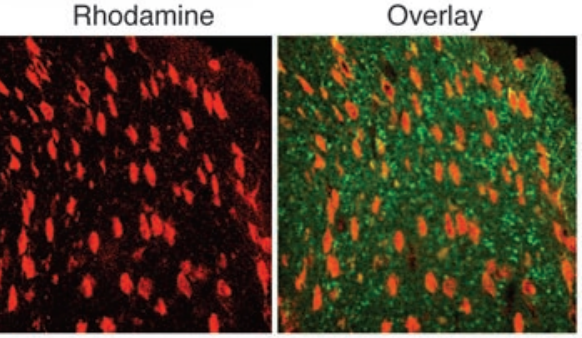

Figure 3

Presence of TAT-PNP in brain tissue from treated $\mathrm{PNP}^{-/-}$mice. (A) Threeweek-old PNP-/- mice were injected i.p. with $2.5 \mathrm{U} / \mathrm{g}$ body wt of TAT-PNP or nonfused PNP and sacrificed 4 hours later. Brain sections of mice were stained with rabbit anti-human PNP followed by Alexa 488-conjugated anti-rabbit antibodies and visualized by confocal microscopy. Arrow indicates blood vessel. Original magnification, $\times 200$. (B) Brain sections obtained as described in A were also stained with mouse anti-neuronal nuclei antibodies. Rhodamineconjugated anti-mouse was used as a secondary antibody. Original magnification, $\times 400$. Images are representative of 3 independent experiments.

an equivalent volume of PBS. Abnormal liver function, reflected by increased levels of aspartate aminotransferase (AST) and alanine aminotransferase (ALT), was observed in 1 of 6 mice treated with 4 U/g/wk TAT-PNP (ALT, 239 U/1; AST, 467 U/1), 1 of 6 mice treated with $8 \mathrm{U} / \mathrm{g} /$ wk TAT-PNP (ALT, $224 \mathrm{U} / \mathrm{l}$; AST, $205 \mathrm{U} / \mathrm{l}$ ), and 2 of 11 normal control littermates (ALT, $147 \mathrm{U} / 1$; AST, $158 \mathrm{U} / \mathrm{l}$; and AST, $452 \mathrm{U} / \mathrm{l})$. Otherwise, even at the highest treatment dose, levels of ALT, AST, urea, creatinine, white blood cells, and platelets $(30.5 \pm 7.9 \mathrm{U} / 1,69.0 \pm 24.7 \mathrm{U} / \mathrm{l}, 6.0 \pm 0.5 \mathrm{mmol} / 1,10.6 \pm 5.1 \mu \mathrm{mol} / \mathrm{l}$, $2.9 \pm 1.0 \times 10^{9} \mathrm{cells} / 1$, and $1.24 \pm 0.45 \times 10^{12}$ cells $/ 1$, respectively) remained comparable to those of age-matched control littermates $(29.4 \pm 11.3 \mathrm{U} / \mathrm{l}, 90.5 \pm 36.3 \mathrm{U} / 1,6.1 \pm 0.5 \mathrm{mmol} / \mathrm{l}, 26.4 \pm 12.1 \mu \mathrm{mol} / \mathrm{l}$, $1.7 \pm 0.4 \times 10^{9}$ cells $/ 1$, and $1.14 \pm 0.42 \times 10^{12}$ cells $/ 1$, respectively).

TAT-PNP is detected in the brains of $\mathrm{PNP}^{-/-}$mice. Neurological abnormalities are often found in PNP-deficient patients, although they have not been described in $\mathrm{PNP}^{-/-}$mice. Therefore, we were particularly interested in evaluating the ability of TAT-PNP to cross the blood-brain barrier. $\mathrm{PNP}^{-/-}$mice were sacrificed 4 hours after injection of TAT-PNP or nonfused PNP. Brain sections were stained with rabbit anti-human PNP antibodies that we generated followed by fluorescent Alexa 488-conjugated anti-rabbit antibodies and visualized by confocal microscopy. Fluorescence was observed after TAT-PNP treatment (Figure 3A). Overlay of the phase contrast and fluorescence images demonstrated that TAT-PNP diffused beyond the proximity of blood vessels (Figure 3A, arrow), into the brain tissue. In marked contrast, brain sections from mice treated with nonfused PNP showed no fluorescence, which also suggested that the delivery of PNP by TAT into the brain was not due to disrupted blood-brain barriers in the $\mathrm{PNP}^{-/-}$mice or an artifact created by our techniques. Moreover, costaining of brain sections with a neuronal-specific antibody demonstrated that TAT-PNP transduced both neuronal and nonneuronal cells (Figure 3B). Finally, to confirm the ability of TAT-PNP to reach all brain areas, active protein was recovered following treatment from several brain structures. Twenty-four hours after TAT-PNP administration, PNP activity in the frontal cortex, parietal cortex, and cerebellum was $1.7 \pm 0.7,2.5 \pm 1.2$, and $1.8 \pm 0.9 \mathrm{nmol} / \mathrm{min} / \mathrm{mg}$ protein, respectively, which paralleled PNP activity found in corresponding brain sections from normal control littermates $(11.7 \pm 2.2,10.4 \pm 1.5$, and $10.4 \pm 1.2 \mathrm{nmol} / \mathrm{min} / \mathrm{mg}$ protein, respectively). These results demonstrate the ability of TAT PTD treatment to effectively deliver active PNP across the blood-brain barrier.

TAT does not increase the immune response to PNP. Full-length TAT protein has previously been shown to induce a vigorous immune response $(34,35)$. However, there have not been any reports to our knowledge documenting whether fusion with the short (11-amino acid) TAT PTD peptide increases the immunogenicity of the associated molecule. To determine whether TAT enhanced the immune response of $\mathrm{PNP}^{-/-}$mice to PNP, an ELISA was developed to detect the presence of IgG antibodies against TAT-PNP and nonfused PNP. Within 2-3 weeks of treatment with TAT-PNP and nonfused PNP, we detected antibodies against TAT-PNP and nonfused PNP, respectively (Figure 4). Antibodies to TAT-PNP and nonfused PNP reached maximal levels - which were indistinguishable $(\mathrm{OD}, 3.794 \pm 0.436$ and $3.846 \pm 0.771$, respectively, at a serum dilution of $1: 100)$ - after 7-8 weeks. In addition, $\mathrm{PNP}^{-/-}$mice treated with TAT-PNP had similar titers of antibodies to nonfused PNP (OD, $3.833 \pm 0.122$ ), and mice treated with nonfused PNP had similar titers of antibodies to TAT-PNP (OD, $3.626 \pm 0.219)$. This finding, together with our observation that serum containing antibodies to TAT-PNP did not react with another PTD-fused protein that we produced, TAT-TEL/ETV6 (data not shown), suggests that the immune response observed in TAT-PNP-treated mice was not against TAT itself, but rather against the xenogeneic human PNP.

Intracellular delivery of PNP by TAT protects the enzyme from neutralizing antibodies. The detection of antibodies to PNP raised concerns that these antibodies could neutralize enzyme activity. Therefore, we studied the biological significance of anti-PNP antibodies in vitro by neutralization assay using PNP-deficient human cells, which were established from a patient diagnosed with PNP deficiency (40), and in vivo by examining uric acid production, which reflects PNP activity. Initially we demonstrated that serum with high titers of antibodies to TAT-PNP neutralized enzyme activity (Figure 5A). Such serum reduced the enzyme activity of TAT-PNP from $93 \% \pm 5 \%$ to $57 \% \pm 5 \%$ and of nonfused PNP from $96 \% \pm 5 \%$ to 


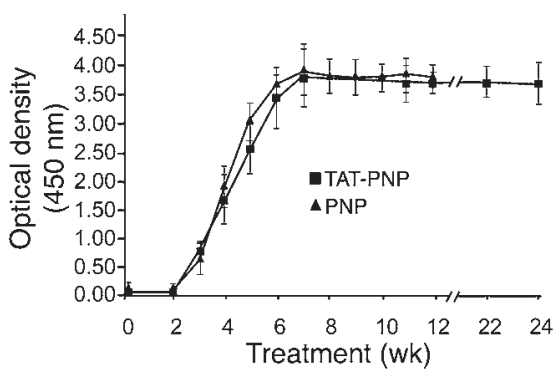

Figure 4

TAT-PNP and nonfused PNP treatment induced development of antibodies to PNP. Three-week-old PNP ${ }^{-1-}$ mice were injected i.p. twice weekly with $0.5 \mathrm{U} / \mathrm{g}$ body wt of TAT-PNP or nonfused PNP (5-8 mice per group). Serum samples, drawn at the indicated time points during 24 weeks of TAT-PNP treatment (squares) or 12 weeks of treatment with nonfused PNP (triangles) were assessed for the presence of antibodies by ELISA. Serum samples were diluted 1:100 and added for 2 hours to plates coated with TAT-PNP or nonfused PNP $(5 \mu \mathrm{g} / \mathrm{ml})$. Following washes, HRP-labeled anti-mouse IgG was added. The assay was developed using TMB substrate. OD was read at $450 \mathrm{~nm}$. Results are mean \pm SD.

$61 \% \pm 3 \%$, reflecting the neutralizing capacity of the serum. In parallel we confirmed, as expected, that incubation of PNP-deficient cells (without the neutralizing serum) with TAT-PNP, but not with nonfused PNP, significantly increased enzyme activity within the cells (up to $56 \% \pm 3 \%$ of normal cells), demonstrating the ability of TAT to transduce PNP into cells. Importantly, coincubation of the neutralizing serum and PNP-deficient cells with TAT-PNP or nonfused PNP resulted in a significant increase $(P<0.005)$ in enzyme activity within the cells to $35 \% \pm 5 \%$, revealing that TAT-PNP was still delivered into the cells. Thus, despite the presence of neutralizing antibodies, the fusion protein does reach the cells. A similar ability to evade neutralization was observed in vivo. Uric acid was measured in the urine of $\mathrm{PNP}^{-/-}$mice every $1-3$ weeks, at least 24 hours after injection of TAT-PNP. Despite the development of antiPNP antibodies, $\mathrm{PNP}^{-/-}$mice treated with TAT-PNP continued to produce uric acid, indicating that the enzyme was still biologically effective in vivo (Figure 5B). Our results show that although the fusion protein induced antibody formation, the rapid intracellular delivery by TAT partially protected PNP from neutralization.

TAT-PNP prevents immune dysfunction and early death of $\mathrm{PNP}^{-/-}$mice. The hallmark of abnormal PNP function is severe T cell immunodeficiency. Hypoplastic thymi, markedly reduced number of total and double-positive thymocytes, decreased numbers of $\mathrm{T}$ lymphocytes, and abnormal $\mathrm{T}$ lymphocyte responses are found in $\mathrm{PNP}^{-/-}$mice (3). We hypothesized that adequate replacement of PNP would correct these abnormalities. Three-week-old PNP-/mice were injected i.p. twice weekly with TAT-PNP or nonfused PNP, both at $0.5 \mathrm{U} / \mathrm{g}$ body wt, or PBS and compared with normal control littermates. To determine the effect of TAT-PNP PTD on $\mathrm{T}$ cell abnormalities in PNP deficiency, we assessed thymus development and $\mathrm{T}$ lymphocyte function in $\mathrm{PNP}^{-/-}$mice after 12 weeks of treatment. TAT-PNP administration was associated with a significant increase in thymus weight to $41 \pm 9 \mathrm{mg}$ compared with $11 \pm 6 \mathrm{mg}$ in PBS-treated $\mathrm{PNP}^{-/-}$mice, which was similar to the $52 \pm 5 \mathrm{mg}$ thymus weight in normal control littermates. Nonfused PNP injections also increased thymus weight $(24 \pm 7 \mathrm{mg})$, but to a significantly lesser extent $(P=0.002)$. Furthermore, as demon- strated in Figure 6A, 12 weeks of TAT-PNP treatment significantly improved the number of thymocytes in the thymi of $\mathrm{PNP}^{-/-}$mice $\left(116 \pm 15 \times 10^{6}\right.$ cells $)$, compared with PBS-treated $\mathrm{PNP}^{-/-}$mice $\left(38 \pm 14 \times 10^{6}\right.$ cells), to near normal levels (control, $143 \pm 8 \times 10^{6}$ cells). Treatment with TAT-PNP also significantly increased the number of double-positive thymocytes in $\mathrm{PNP}^{-/-}$mice (Figure 6B). While PBS-treated $\mathrm{PNP}^{-/-}$mice had only $25 \pm 2 \times 10^{6}$ double-positive thymocytes, mice treated for 12 weeks with TAT-PNP had $87.9 \pm 6.2 \times 10^{6}$ cells or $72 \% \pm 5 \%$ of the double-positive thymocytes found in normal control littermates. In parallel to thymus normalization in $\mathrm{PNP}^{-/-}$mice with TAT-PNP treatment, there were also striking improvements in $\mathrm{T}$ cell numbers and function in the periphery. T lymphocyte percentage in the spleens of $\mathrm{PNP}^{-/-}$ mice injected with PBS was only $12.6 \% \pm 6.0 \%$, while treatment with TAT-PNP significantly increased the percentage to $34.3 \% \pm 2.5 \%$ $(P<0.0001)$, similar to the $38.3 \% \pm 9 \%$ found in the spleens of healthy control littermates (Figure 6C). Improvement was also seen in the percentage of $\mathrm{T}$ lymphocytes in the lymph nodes of $\mathrm{PNP}^{-/-}$mice treated with TAT-PNP (data not shown). To evaluate the function of these cells, spleen-derived T lymphocytes were stimulated in vitro with anti-CD3 (Figure 6D). Stimulation indexes of lymphocytes from PBS-treated $\mathrm{PNP}^{-/-}$mice were extremely reduced $(5 \pm 1)$ compared with those of normal control littermates $(85 \pm 21)$. Following 12 weeks' treatment with TAT-PNP, a greater than 12 -fold improvement in lymphocyte response was achieved $(63 \pm 16)$, which was significantly better $(P<0.05)$ than the responses of mice treated with nonfused PNP $(31 \pm 7)$. Our findings demonstrate that treatment with TAT-PNP for 12 weeks significantly improves immunity in $\mathrm{PNP}^{-/-}$mice.

$\mathrm{PNP}^{-/-}$mice often suffer from massively enlarged spleen and weight loss until their death at 7-11 weeks of age. We anticipated that effective treatment and correction of the immune defects in $\mathrm{PNP}^{-/-}$mice would subsequently prevent the splenomegaly, weight loss and early death. Three-week-old $\mathrm{PNP}^{-/-}$mice (8-15 per group) were injected with TAT-PNP, nonfused PNP, or PBS twice weekly. Following 12 weeks of TAT-PNP treatment, the weight of the spleens $(0.18 \pm 0.02 \mathrm{~g})$ was significantly lower $(P<0.01)$ than in PBS-treated mice $(0.35 \pm 0.05 \mathrm{~g})$ or nonfused PNP treated mice $(0.30 \pm 0.02 \mathrm{~g})$. Also, $\mathrm{PNP}^{-/-}$mice treated for 12 weeks with TAT-PNP maintained their body weights $(23.9 \pm 1.0 \mathrm{~g})$ to near that of normal control littermates $(24.8 \pm 2.7 \mathrm{~g})$, which was significantly higher $(P<0.001)$ than the $20.3 \pm 1.1 \mathrm{~g}$ or $17.3 \pm 0.5 \mathrm{~g}$ body wt of $\mathrm{PNP}^{-/-}$mice treated with nonfused PNP or PBS, respectively. Importantly, after 12 weeks, 8 of 8 (100\%) and 10 of 13 (76.9\%) of $\mathrm{PNP}^{-/-}$mice that were injected with PBS or nonfused PNP, respectively, succumbed. In marked contrast, only 2 of 15 (13.3\%) of $\mathrm{PNP}^{-/-}$mice treated with TAT-PNP died.

Prolonged TAT-PNP PTD treatment continues to normalize immune function and survival of $\mathrm{PNP}^{-/-}$mice. The data presented above demonstrate that 12 weeks of TAT-PNP treatment prevent the immunological abnormalities and early death of $\mathrm{PNP}^{-/-}$mice. Yet it was not clear whether TAT-PNP PTD remains effective over extended periods, as would be required of a potentially long-term course of enzyme replacement therapy. Therefore, we followed the immune function and outcome of an additional $22 \mathrm{PNP}^{-/-}$mice over 24 weeks of TAT-PNP PTD treatment $(n=5-6$ mice in 4 separate experiments using different enzyme preparations). The results of the long-term administration of TAT-PNP PTD were compared only to those of age-matched normal control littermates because, as described above, almost all $\mathrm{PNP}^{-/-}$mice treated with $\mathrm{PBS}$ or 


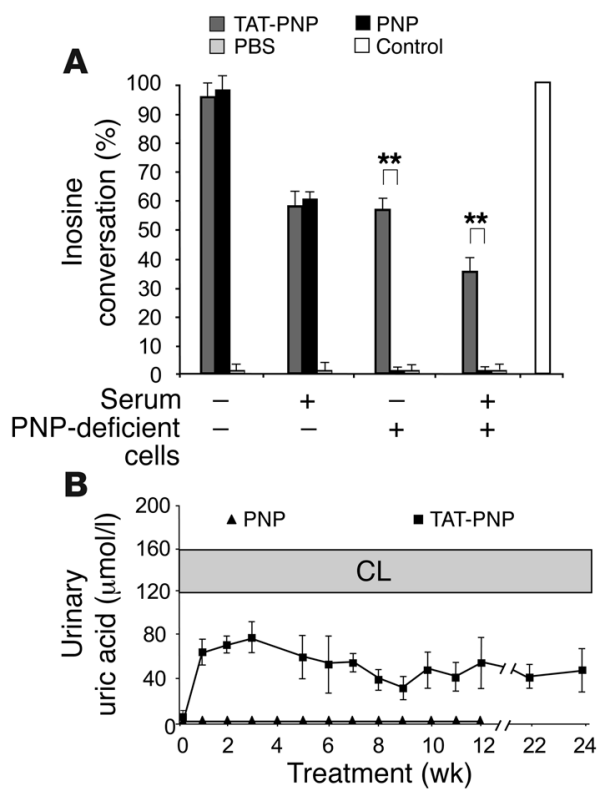

Figure 5

Anti-PNP antibodies neutralize TAT-PNP but do not prevent intracellular TAT-PNP transduction. (A) Serum from $\mathrm{PNP}^{-/-}$mice treated with TAT-PNP, which contained antibodies to PNP that neutralized PNP enzyme activity, yet TAT-PNP still delivered active enzyme into PNP-deficient cells. Enzyme activity $\left({ }^{14} \mathrm{C}\right.$-labeled inosine conversion) was measured after 20 minutes' incubation of TAT-PNP or nonfused PNP, both at $0.1 \mathrm{U} / \mathrm{ml}$, or PBS in the absence or presence of serum containing antibodies to TAT-PNP (diluted 1:100). Following similar incubation in the absence or presence of $2 \times 10^{5}$ PNP-deficient cells, activity was measured in the cell pellets. Results are representative of 3 independent experiments and are presented relative to the activity in normal control cells. ${ }^{* *} P<0.005$. (B) In spite of increasing concentrations of antibodies to TAT-PNP during treatment of $\mathrm{PNP}^{-1-}$ mice with TAT-PNP, uric acid production (which is dependent on active PNP in vivo) was not affected. Twenty-four hours or later after injecting $\mathrm{PNP}^{-/-}$mice with TAT-PNP (squares), uric acid concentrations were measured in the urine and compared with uric acid from $\mathrm{PNP}^{-/-}$mice treated with nonfused PNP (triangles). Results (converted to $\mu \mathrm{mol} / \mathrm{l}$ ) are mean \pm SD of urine samples collected from 6-15 mice and are compared with normal control littermates.

nonfused PNP died within 12 weeks of treatment. After injecting TAT-PNP for 24 weeks, the thymus weight of $\mathrm{PNP}^{-/-}$mice $(26 \pm 3 \mathrm{mg})$ was practically identical to that of age-matched control mice $(31 \pm 6 \mathrm{mg})$. Also, the absolute numbers of total thymocytes $\left(98.2 \pm 7.6 \times 10^{6}\right)$ and double-positive thymocytes $\left(76.9 \pm 8.6 \times 10^{6}\right)$ were similar to those of age-matched controls (Figure 7A). In addition, the percentage of $\mathrm{T}$ lymphocytes in the spleens of TAT-PNP PTD-treated PNP-/- mice $(32.4 \% \pm 4.2 \%)$ was indistinguishable from that of age-matched normal control littermates $(36.3 \% \pm 1.8 \%)$. Further evidence for continued normalization of immune function in $\mathrm{PNP}^{-/-}$mice following 24 weeks' treatment with TAT-PNP (Figure 7B) was the response of $\mathrm{T}$ lymphocytes from spleen and lymph nodes to CD3 (stimulation index, $66 \pm 13$ and $82 \pm 8$, respectively), which was comparable to those of age-matched controls (stimulation index, $84 \pm 21$ and $96 \pm 20$, respectively). Strikingly, while all $20 \mathrm{PNP}^{-/-}$mice injected with PBS died, a highly significant $(P<0.001)$ improvement in survival was seen following TAT-PNP PTD administration, with 17 of 22 (77.3\%) TAT-PNP- injected $\mathrm{PNP}^{-/}$- mice still alive after 24 weeks of treatment (Figure 7C). Together these results conclusively demonstrate the benefit of longterm TAT-PNP enzyme replacement therapy for PNP deficiency.

\section{Discussion}

Defects in PNP enzyme activity result in accumulation of toxic purine metabolites and fatal immune dysfunction. Previous studies of PNP deficiency and other purine defects, such as ADA deficiency, suggest that correction of the metabolic abnormalities is followed by improved immune function $(8,10,39,41)$. In addition, as PNP is a cytoplasmic enzyme (42), we hypothesized that efficient intracellular PNP delivery would correct the metabolic and immune abnormalities and extend survival in PNP deficiency. Moreover, we expected that data gathered during prolonged use of full-length enzyme fused to a PTD in an animal model would be important for future treatment of patients with similar proteins.

To test these hypotheses, we fused the human PNP to the TAT HIV-1 PTD. We used the $\mathrm{PNP}^{-/}$mouse model to closely follow the effects of fusion on the retention, distribution, and immunogenicity of PNP in vivo. Nonfused PNP was rapidly removed from the circulation into the urine and was undetectable in blood or tissues within several hours. In marked contrast, TAT fusion prevented PNP excretion into the urine and induced rapid delivery of PNP into cells, which resulted in detection of PNP in various organs 8 hours after a single injection. Moreover, uric acid production, which depends on PNP enzyme activity, was detected for more than 24 hours after TAT-PNP PTD administration, demonstrating that PTD fusion significantly extends the biological effect of the molecules in vivo, which is in agreement with previous studies (43-45). In addition, our study, which is the first to our knowledge to follow in an animal model the effects of repeated administration of full-length enzyme fused to PTD over an extended period of time, enabled assessment of the immune response to the fusion protein. The HIV-TAT PTD has previously been shown to elicit strong immune responses $(34,35)$. In contrast, another group demonstrated that TAT PTD failed to enhance the immunogenicity of CMV nucleoprotein in mice, however only a single booster dose was given (29). Thus the ability of the 11 amino acids of HIV-TAT to induce an immune response was unclear (46). As expected, we found that the mice did develop antibodies against the foreign human PNP. Yet antibody titers after treatment with TAT-PNP were indistinguishable from those appearing following nonfused PNP administration. Also, antibodies against TAT-PNP reacted similarly to TAT-PNP or nonfused PNP. Furthermore, the antibodies against TAT-PNP did not bind to other TAT-fused proteins, which indicates that these antibodies are directed against PNP itself and not against TAT. Thus, fusion with TAT PTD did not increase the immunogenicity of the protein. Nevertheless, the detection of antibodies to TAT-PNP during TAT-PNP PTD administration raised concern about the long-term efficacy of such treatment. In vitro studies revealed that sera from mice injected with TAT-PNP neutralized PNP enzyme activity, yet we were able to demonstrate that the intracellular delivery of PNP by PTD helped the fusion protein to evade neutralization. Furthermore, in $\mathrm{PNP}^{-}-$- mice, despite the development of anti-PNP antibodies during treatment, TAT-PNP maintained its biological activity as demonstrated by the continued production of uric acid and persistent immune recovery. Thus, we conclude that PTD distributes PNP into the cells, thereby preventing loss of enzyme in the urine and "sheltering" the protein from neutralization. Importantly, the 

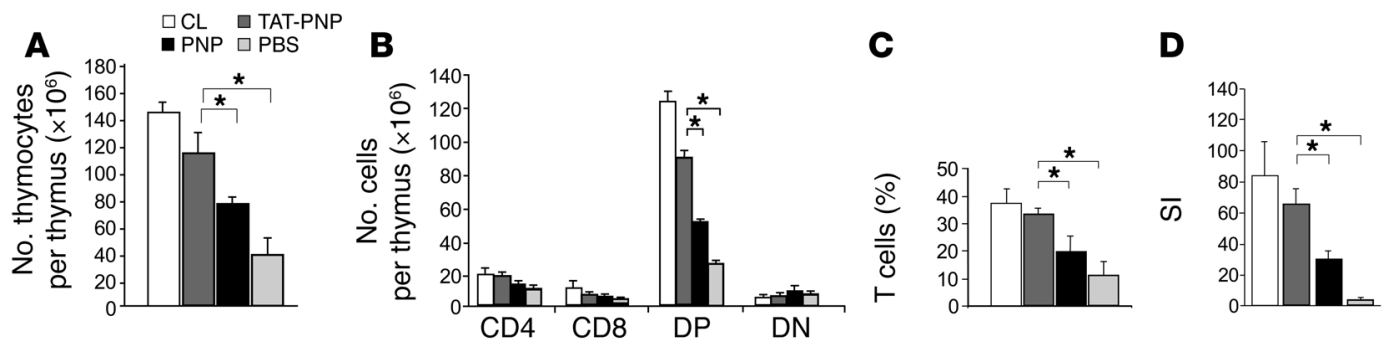

\section{Figure 6}

Treatment of $\mathrm{PNP}^{-1-}$ mice with TAT-PNP prevents abnormalities in thymus and T lymphocyte number and function. Immune function of PNP-/mice following 12 weeks of treatment with $0.5 \mathrm{U} / \mathrm{g}$ body wt of TAT-PNP or nonfused PNP was compared with that of age-adjusted healthy control littermates. (A) TAT-PNP treatment significantly increased the absolute number of thymocytes in the thymus of PNP-l- mice. (B) Analysis of single-cell suspensions from thymus stained with PE- and FITC-conjugated anti-CD4 and anti-CD8 mAbs. Isotype-matched PE- or FITC-labeled antibodies were used as negative controls. Cells expressed $\mathrm{CD}^{+}, \mathrm{CD}^{+}$, or $\mathrm{CD}^{+}{ }^{+} \mathrm{CD} 8^{+}$(double positive; DP) or showed no expression (double negative; DN). TAT-PNP treatment significantly improved the number of DP thymocytes in $\mathrm{PNP}^{-/-}$mice. (C) Analysis of the percentage of T cells in the spleen by flow cytometry. Nylon wool single-cell suspensions were stained with PE- and FITC-conjugated anti-CD3 and anti-CD19 mAbs. Isotype-matched PE- or FITC-labeled Abs were used as negative controls. Treatment with TAT-PNP significantly increased the percentage of T lymphocytes in the spleen of PNP-/- mice. (D) T lymphocyte function analysis. T lymphocytes were stimulated in vitro with anti-CD3. Proliferation is expressed as stimulation indexes $(\mathrm{SI})$ of the mean $\mathrm{cpm}$ with stimulation divided by the mean cpm without stimulation. TAT-PNP treatment significantly increased the response of T lymphocytes in the spleen of $\mathrm{PNP}^{-1-}$ mice. Results are mean $\pm \mathrm{SD}$ of $5-10$ mice. ${ }^{*} P<0.05$.

extended in vivo biological activity of proteins fused to PTD may be of significance to other diseases in which rapid loss via the urine or neutralizing antibodies are a major concern.

Using the $\mathrm{PNP}^{-/-}$mouse model and TAT-PNP we also determined the ability of human PNP to substitute for the murine enzyme. Previously, E. coli PNP was shown to be active in mice (47). However, substrate specificities differ among PNPs of different species (48). Nevertheless, because of the greater than $85 \%$ amino acid homology between human and murine PNP, we anticipated that human PNP would also be active in mice. Indeed, TAT-PNP induced uric acid formation in $\mathrm{PNP}^{-/-}$mice, indicating restored purine degradation and thereby confirming that human PNP can phosphorylate purine nucleosides in mice and that $\mathrm{PNP}^{-/-}$mice are suitable for the evaluation of potential therapies for human PNP deficiency. Furthermore, the ability to reverse the metabolic defect in $\mathrm{PNP}^{-/-}$mice suggests that such treatment would also correct the immune function in these mice.

A major objective of this study was to develop treatment for the severe $T$ cell immune defects in PNP-deficient patients. PNPdeficient patients have hypoplastic thymi and severely reduced T lymphocyte number and function (4). In addition, markedly reduced numbers of total and double-positive thymocytes are found in $\mathrm{PNP}^{-/-}$mice (3). We initially demonstrated that TATPNP corrected these immune abnormalities. Treating $\mathrm{PNP}^{-/-}$ mice with TAT-PNP for 12 weeks significantly increased thymus weight as well as the number of total thymocytes and double-
A

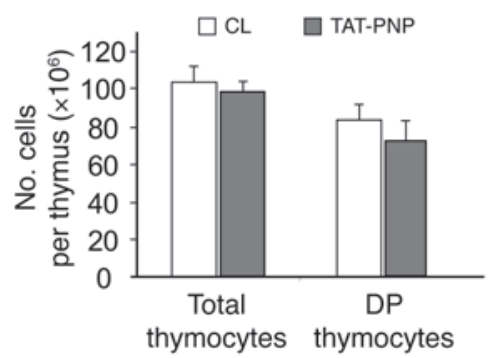

B

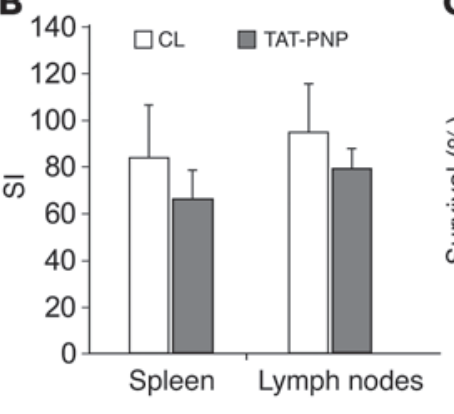

C

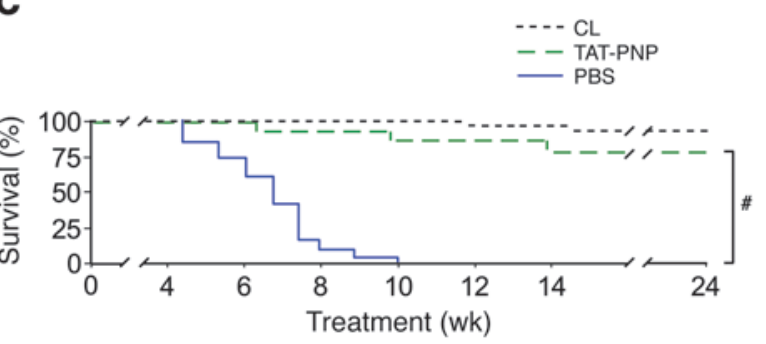

PBS

Figure 7

TAT-PNP PTD treatment for 24 weeks normalizes immune function and survival of PNP ${ }^{-/-}$mice. Twenty-two PNP-/- mice were injected i.p. twice weekly with $0.5 \mathrm{U} / \mathrm{g}$ body wt of TAT-PNP for 24 weeks. Immune function and survival following treatment were not significantly different than those of normal control littermates. (A) Analysis of thymus populations was performed by flow cytometry. Single-cell suspensions from thymi were stained with PE- and FITC-conjugated anti-CD4 and anti-CD8 mAbs. The numbers of total and double-positive thymocytes in thymi of PNP-/- mice after treatment with TAT-PNP were not significantly different than in normal control littermates. (B) Function of T lymphocytes. T lymphocytes isolated from the spleen or lymph nodes were stimulated in vitro with anti-CD3. Response is expressed as stimulation indexes of the mean cpm with stimulation relative to that without stimulation. The stimulation indexes of lymphocytes isolated from PNP-l- mice after 24 weeks of TAT-PNP treatment were not significantly different from those of normal control littermates. (C) Survival of PNP-l- mice treated for 24 weeks with TAT-PNP PTD $(n=22)$ or a similar volume of PBS $(n=20)$ and of normal control littermates $(n=30)$ calculated by the KaplanMeier method. Survival of PNP--- mice after 24 weeks of TAT-PNP treatment (77.3\%) was similar to that of normal controls (93.3\%) and significantly better than that of PBS-treated $\mathrm{PNP}^{-1-}$ mice. ${ }^{\#} P<0.001$. 
positive thymocytes. Moreover, T lymphocytes in the periphery and the response of these cells to stimulation essentially normalized. Previous studies of other immune deficiencies suggest that even a moderate increase in $T$ cell number and function may lead to biological and clinical benefit $(49,50)$. Indeed, improved $\mathrm{T}$ cell function, although not complete, was associated with normalization of spleen size and animal weight and prevention of the early death characteristic of $\mathrm{PNP}^{-/-}$mice. The immune recovery and improved survival in $\mathrm{PNP}^{-/-}$mice during the 12 -week TAT-PNP PTD treatment suggest that TAT-PNP PTD could be used as a temporary replacement, similar to the current practice of injecting PEG-ADA in ADA-deficient patients to improve their condition until hematopoietic stem cell transplant or gene delivery may be attempted $(8,51)$.

Moreover, in many conditions, including hemophilia, ADA deficiency, Gaucher disease, and others, enzyme replacement therapy is used over the course of many years $(37,52-54)$; thus we anticipated that TAT-PNP may also be required for extended periods. Therefore we extended the treatment of TAT-PNP PTD in PNP-/mice, which also provided additional confidence about the successful effect of TAT-PNP PTD treatment on mortality. We found persistent production of uric acid during the 24-week TAT-PNP PTD treatment, which demonstrated that TAT-PNP enzyme remains active in vivo. The extended TAT-PNP treatment maintained the improved immune function including normal thymus weight, maturation of thymocytes, and Tlymphocyte number and function. Most importantly, $77.3 \%$ of $\mathrm{PNP}^{-/-}$mice treated with TAT-PNP for 24 weeks survived, compared with no survival in PBS-treated $\mathrm{PNP}^{-/-}$mice, thereby confirming the benefit of prolonged intracellular PNP delivery for PNP deficiency.

Significant for the future treatment of PNP-deficient patients, we found that immune function was salvaged even when enzyme replacement was initiated at 3 weeks of age, suggesting that the damage to the thymus by toxic purine nucleosides may be reversible, which is relevant for those patients not diagnosed at birth. In addition, we evaluated a regimen of twice weekly injections, which was based on uric acid production and the reported association between correction of the metabolic disturbances and immune reconstitution $(8,40,41)$. Twice weekly injections have been used for many years in ADA-deficient patients that receive PEG-ADA (7) and patients with hypogammaglobulinemia that receive subcutaneous immunoglobulin replacement (55); therefore we anticipate that such a regimen could be implemented clinically. We also demonstrated that the dose of TAT-PNP may be safely increased by as much as 8 -fold, if required. Thus, we conclude that frequent TAT-PNP treatment over prolonged periods safely corrects the immune abnormalities and prevent death in $\mathrm{PNP}^{-/-}$mice and therefore should be considered for patients suffering from PNP deficiency.

We also demonstrated that repeated injections of nonfused PNP had some effect on immune function in $\mathrm{PNP}^{-/-}$mice, similar to the benefit reported in PNP-deficient patients after frequent red blood cell transfusions (8). It was hypothesized that providing the active enzyme outside PNP-deficient cells creates a concentration gradient that removes the toxic purine nucleosides from inside the cells, thereby allowing recovery of the immune system (8). Yet prior studies of PNP-deficient patients (10) and ADAdeficient patients treated for extended periods with extracellular enzyme replacement therapy such as PEG-ADA have shown the benefit was only partial $(52,53)$. Similarly, we observed limited benefit with nonfused PNP treatment, possibly reflecting an inability to adequately transfer nucleosides across membranes, which is dependent on nucleoside transporters (56).

An additional benefit for PNP deficiency may be the ability of TAT to deliver the missing enzyme into the brain. $\mathrm{PNP}^{-/-}$mice do not exhibit distinctive neurological defects, and the precise mechanisms for brain damage or the effect on central nervous cells caused by PNP deficiency are not known. Nevertheless, PNP is ubiquitously expressed, thus restoring PNP activity in all brain tissues would be advantageous. Indeed, our experiments revealed that TAT carries active PNP to neuronal and nonneuronal cells in various brain areas, similar to previous reports that showed effective brain delivery of several PTD fusion proteins, such as Bcl- $\mathrm{x}_{\mathrm{L}}$ and JNK inhibitor $(43,44,57)$. Thus, while TAT-PNP improved immune function and survival in $\mathrm{PNP}^{-/-}$mice, it may also help the neurological abnormalities in PNP-deficient patients. Furthermore, the unique ability of PTD to penetrate the blood-brain barrier and distribute active enzyme into brain cells, which most protein delivery systems or gene therapies are unable to achieve, may be advantageous for diseases involving inherited enzyme deficiencies in brain cells such as Lesch-Nyhan disease, mucopolysaccharidosis, Gaucher disease, and others $(58,59)$.

In conclusion, we have demonstrated the efficiency of prolonged intracellular delivery of PNP using TAT PTD, thereby providing what we believe to be a novel method of treatment for PNP deficiency. PTD may also be applicable for other diseases and conditions that require repeated intracellular delivery of enzymes or full length proteins in vivo.

\section{Methods}

Cloning, expression, and purification of TAT-PNP. As described in Figure 1B, the ATG of the human PNP (NM_000270) was replaced with the coding sequence of the 11-amino acid TAT PTD (YGRKKRRQRRR) flanked by glycine residues using PCR (37). TAT-PNP and PNP without the TAT domain (nonfused PNP) were inserted into PRSET vector (Invitrogen) with an $\mathrm{N}$-terminal Histidine tag (6XHis) and expressed in E. coli BL21(DE3). Transformed bacteria were allowed to grow for 24 hours at $37^{\circ} \mathrm{C}$ without IPTG, followed by gentle lysis (B-PER Bacterial lysis buffer; Pierce). The lysate was applied to a TALON resin column (BD Biosciences) and washed with $15 \mathrm{mM}$ imidazole buffer ( $50 \mathrm{mM}$ sodium phosphate, $300 \mathrm{mM} \mathrm{NaCl}$ ). The resin-bound protein was eluted with $250 \mathrm{mM}$ imidazole buffer. Proteins were desalted on a PD-10 column (Amersham Biosciences). The activities of both TAT-PNP and nonfused PNP were adjusted to an average of $1 \mathrm{U} / 10.2 \mu \mathrm{g}$ protein (as determined by the enzyme assay described below). Due to the strong binding of the positively charged TAT to cell surfaces, possibly through heparan sulfate glycosaminoglycans, we stripped membrane-bound proteins by washing samples thoroughly at a low $\mathrm{pH}$.

Mutant mice. $\mathrm{PNP}^{-/-}(\mathrm{C} 57 \mathrm{BL} / 6)$ mice, in which the catalytic domain was disrupted, were described previously (3). PNP deficiency was confirmed by the absence of PNP enzyme activity in whole blood samples obtained from the tails of 18- to 20-day-old mice. Mice were housed in cages with autoclaved bedding and equipped with filter caps under containment protocols. Healthy normal littermates were used as a control. The Institutional Research and Ethics Committee of the Hospital for Sick Children approved all procedures and experiments.

Transduction of TAT-PNP into PNP-/- mice. To study the distribution of the proteins in the mice, $\mathrm{PNP}^{-/-}$mice were injected i.p. with $2.5 \mathrm{U} / \mathrm{g}$ body wt TAT-PNP or nonfused PNP. Urine, serum, and blood samples were collected before and after the injections at different time points. Mice were sacrificed after 4 or 8 hours, and organs were used to prepare cell suspensions. 
The biological integrity of the transduced proteins was evaluated in the cells and tissues by PNP activity assay. Organs were also flash-frozen in liquid nitrogen for fluorescence studies: tissues were fixed with $4 \%$ paraformaldehyde, permeabilized with $0.25 \%$ Triton X-100 in PBS, and blocked with $5 \%$ BSA. Internalization of the fusion proteins into tissues was analyzed by confocal microscopy. The tissues were stained with rabbit anti-human PNP antibodies that we produced. Briefly, PNP coupled to keyhole limpet hemocyanin was used to immunize New Zealand white rabbits. Antibodies to PNP were purified by affinity chromatography from serum collected 10 weeks later. Secondary donkey Alexa 488-conjugated anti-rabbit antibody (Invitrogen) was added to visualize the recombinant proteins by confocal microscopy. Brain sections were also stained with mouse anti-neuronal nuclei NeuN antibody (Chemicon) and secondary goat rhodamine-conjugated anti-mouse antibody (Invitrogen).

PNP enzyme activity. PNP enzyme activity was determined by measuring inosine conversion to hypoxanthine as previously described (3). Briefly, ${ }^{14} \mathrm{C}$-labeled inosine (Movarek Biochemicals) was added to whole cell lysate or purified enzyme at $37^{\circ} \mathrm{C}$. The unconverted substrate and the product were separated by thin-layer chromatography (Fischer Scientific), and the appropriate spots were counted. One unit was defined as the amount of enzyme required to convert $1 \mu \mathrm{mol}$ of inosine to hypoxanthine in 1 minute at $37^{\circ} \mathrm{C}$. Results of the activity assay were expressed as the percentage of conversion of the substrate relative to the activity of $\mathrm{PNP}^{+/+}$controls.

Uric acid concentration analysis. Urinary uric acid concentration was determined with a commercial assay (Thermo Electron Corp.). The color intensity, which is directly proportional to the uric acid concentration in the sample, was measured by spectrophotometer absorbency at $520 \mathrm{~nm}$ and converted to $\mu \mathrm{mol} / \mathrm{l}$ according to the manufacturer's instructions.

Adverse effects with dose escalation. $\mathrm{PNP}^{-/-}$mice and their littermates were injected with increasing doses of TAT-PNP $(1,2,4$, and $8 \mathrm{U} / \mathrm{g}$ body wt/wk). Liver (AST and ALT), kidney (creatinine and urea), and hematological (white blood cells and platelet counts) indexes were determined 4 weeks after treatment and compared with those of age-matched littermates.

Enzyme treatment. Three-week-old $\mathrm{PNP}^{-/-}$mice (5-6 per group) were injected i.p. twice weekly with $0.5 \mathrm{U} / \mathrm{g}$ body wt using different TAT-PNP preparations for 12 or 24 weeks. Similarly, $\mathrm{PNP}^{-/-}$mice were injected with nonfused PNP or the same volume of PBS.

ELISA for detection of antibodies against TAT-PNP or nonfused PNP. Flat-bottomed maxisorb microtiter plates (Nalge Nunc International) were coated with TAT-PNP or nonfused PNP at a concentration of $5 \mu \mathrm{g} / \mathrm{ml}(80 \mu \mathrm{l} /$ well). After incubation at $4{ }^{\circ} \mathrm{C}$ overnight, plates were washed, blocked for 2 hours with $1 \%$ BSA in PBS at room temperature, and washed again. Mice serum samples, diluted 1:100, were added for 2 hours at room temperature in triplicate. The plates were then washed, and a 1:5,000 dilution of HRP-labeled anti-mouse IgG (Amersham Biosciences) was added for 1 hour at room temperature, followed by washes. The assay was developed using TMB substrate (Sigma-Aldrich), and reaction was stopped after 30 minutes by addition of $2 \mathrm{~N} \mathrm{HCl}$. OD was read at $450 \mathrm{~nm}$. Serum containing antibodies to TAT-PNP was also evaluated for its ability to bind an unrelated TAT-fusion protein, the TEL/ETV6 tumor suppressor factor (NM_001987), which was produced by a technique similar to that for TAT-PNP. ELISA was performed as described above except that plates were coated with TAT-TEL/ETV6 (5 and $10 \mu \mathrm{g} / \mathrm{ml})$ and serum was diluted at 1:20, 1:100, and 1:500.

Antibody neutralization assay. PNP enzyme activity was determined following 20 minutes' incubation of serum samples from mice found to have high titers of antibodies to TAT-PNP or nonfused PNP (diluted 1:100) with TAT-PNP or nonfused PNP $(0.1 \mathrm{U} / \mathrm{ml})$. Similarly, activity was measured after the diluted sera and TAT-PNP or nonfused PNP were incubated in the presence of $4 \times 10^{5} \mathrm{PNP}$-deficient human cells, which were established by EBV transformation of $B$ lymphocytes from a patient diagnosed with PNP deficiency (40). PNP enzyme activity was assessed in the cell pellet as described above. All results were expressed relative to the activity of EBVtransformed B lymphocytes from normal controls.

Lymphocyte population and function analysis. For lymphocyte population studies, single-cell suspensions from thymi, spleens, and lymph nodes were prepared in PBS containing 1\% fetal calf serum and stained with PE- and FITC-conjugated (BD Biosciences - Pharmingen) anti-CD3, anti-CD4, anti-CD8, and anti-CD19 mAbs for 30 minutes at $4{ }^{\circ} \mathrm{C}$. Isotype-matched PE- or FITC-labeled antibodies were used as negative controls. Two-color fluorescence analysis was performed using a FACScan flow cytometer (BD Biosciences). For proliferation assays, $\mathrm{T}$ lymphocytes from spleens and lymph nodes (150,000 cells/well) were obtained by nylon wool separation and cultured in the absence or presence of $10 \mu \mathrm{g} / \mathrm{ml}$ anti-CD3 (BD) in microtiter plates (Falcon; BD) for 48 hours followed by a pulse of 16 hours with $0.5 \mu \mathrm{Ci}\left[{ }^{3} \mathrm{H}\right]$ thymidine $(5 \mathrm{Ci} / \mathrm{mmol}$; Amersham Biosciences). Triplicate cultures were incubated in $5 \% \mathrm{CO}_{2}$ at $37^{\circ} \mathrm{C}$. Results were expressed as stimulation indexes, the ratio of the mean cpm following stimulation divided by the mean cpm without stimulation.

Statistics. Values are expressed as mean \pm SD. The statistical significance of differences between 2 groups was determined by 2 -tailed Student's $t$ test, while the differences among 3 or more groups was determined by ANOVA with Tukey's post-hoc comparison adjustment for multiple comparisons. For data measured at multiple time points, repeated-measures ANOVA was used with multiple testing adjustments. Survival rates were evaluated by Kaplan-Meier survival analysis. Log-rank tests were used to test the difference in survival, and for pairwise comparisons Scheffe's multiple comparisons test for strata homogeneity was used. A $P$ value less than 0.05 was considered significant.

\section{Acknowledgments}

We thank A. Cohen for his insightful discussions, C.M. Roifman for providing the $\mathrm{PNP}^{-/-}$mice, and N. Sharfe for comments and review of the manuscript. We also thank Shaun Lee for excellent technical assistance and animal care. This work was supported by a grant from the Canadian Institute for Health Research (to E. Grunebaum).

Received for publication March 16, 2005, and accepted in revised form July 18, 2006.

Address correspondence to: Eyal Grunebaum, 555 University Avenue, Toronto, Ontario M5G 1X8, Canada. Phone: (416) 813-8623; Fax: (416) 813-8624; E-mail: eyal.grunebaum@sickkids.ca.
1. Cohen, A., Grunebaum, E., Arpaia, E., and Roifman, C.M. 2000. Immunodeficiency caused by purine nucleoside phosphorylase deficiency. In Immunology and allergy clinics of North America. Volume 20. C.M. Roifman, editor. WB Saunders Company. Philadelphia, Pennsylvania, USA. 143-159.

2. Grunebaum, E., Zhang, J., and Roifman, C.M 2004. Novel mutations and hot-spots in patients with purine nucleoside phosphorylase deficiency. Nucleosides Nucleotides Nucleic Acids. 23:1411-1415.
3. Arpaia, E., et al. 2000. Mitochondrial basis for immune deficiency. Evidence from purine nucleoside phosphorylase-deficient mice. J. Exp. Med. 191:2197-2208.

4. Markert, M.L. 1991. Purine nucleoside phosphorylase deficiency. Immunodefic. Rev. 3:45-81.

5. Grunebaum, E., and Roifman, C.M. 2002. Gene abnormalities in patients with hemophagocytic lymphohistiocytosis. Isr. Med. Assoc. J. 4:366-369.

6. Pelled, D., Sperling, O., and Zoref-Shani, E. 1999.
Abnormal purine and pyrimidine nucleotide content in primary astroglia cultures from hypoxanthine-guanine phosphoribosyltransferase-deficient transgenic mice. J. Neurochem. 72:1139-1145.

7. Tezcan, I., et al. 1995. A case of adenosine deaminase-negative severe combined immunodeficiency with neurological abnormalities. Turk. J. Pediatr. 37:383-389.

8. Hershfield, M.S. 1998. Adenosine deaminase deficiency: clinical expression, molecular basis, and 
therapy. Semin. Hematol. 35:291-298.

9. Rich, K.C., Majias, E., and Fox, I.H. 1980. Purine nucleoside phosphorylase deficiency: improved metabolic and immunologic function with erythrocyte transfusions. N. Engl. J. Med. 303:973-977.

10. Markert, M.L., Hershfield, M.S., Schiff, R.I., and Buckley, R.H. 1987. Adenosine deaminase and purine nucleoside phosphorylase deficiencies: evaluation of therapeutic interventions in eight patients. J. Clin. Immunol. 7:389-399.

11. Baguette, C., et al. 2002. Persistent developmental delay despite successful bone marrow transplantation for purine nucleoside phosphorylase deficiency. J. Pediatr. Hematol. Oncol. 24:69-71.

12. Myers, L.A., Hershfield, M.S., Neale, W.T., Escolar, M., and Kurtzberg, J. 2004. Purine nucleoside phosphorylase deficiency (PNP-def) presenting with lymphopenia and developmental delay: successful correction with umbilical cord blood transplantation. J. Pediatr. 145:710-712

13. Wadia, J.S., and Dowdy, S.F. 2003. Modulation of cellular function by TAT mediated transduction of full-length proteins. Curr. Protein Pept. Sci. 4:97-104.

14. Frankel, A.D., and Pabo, C.O. 1988. Cellular uptake of the tat protein from human immunodeficiency virus. Cell. 55:1189-1193.

15. Green, M., and Loewenstein, P.M. 1988. Autonomous functional domains of chemically synthesized human immunodeficiency virus tat transactivator protein. Cell. 55:1179-1188.

16. Cohen, S.S., et al. 1999. Pronounced acute immunosuppression in vivo mediated by HIV Tat challenge. Proc. Natl. Acad. Sci. U. S. A. 96:10842-10847.

17. Perez, F., et al. 1992. Antennapedia homeobox as a signal for the cellular internalization and nuclear addressing of a small exogenous peptide. J. Cell. Sci. 102:717-722.

18. Murphy, A.L., and Murphy, S.J. 1999. Catch VP22: the hitch-hiker's ride to gene therapy? Gene Ther. 6:4-5

19. Console, S., Marty, C., Garcia-Echeverria, C., Schwendener, R., and Ballmer-Hofer, K. 2003. Antennapedia and HIV transactivator of transcription (TAT) "protein transduction domains" promote endocytosis of high molecular weight cargo upon binding to cell surface glycosaminoglycans. J. Biol. Chem. 278:35109-35114.

20. Wadia, J.S., Stan, R.V., and Dowdy, S.F. 2004. Transducible TAT-HA fusogenic peptide enhances escape of TAT-fusion proteins after lipid raft macropinocytosis. Nat. Med. 10:310-315

21. Schwarze, S.R., Ho, A., Vocero-Akbani, A., and Dowdy, S.F. 1999. In vivo protein transduction: delivery of a biologically active protein into the mouse. Science. 285:1569-1572.

22. Nagahara, H., et al. 1998. Transduction of fulllength TAT fusion proteins into mammalian cells TAT-p27Kip1 induces cell migration. Nat. Med. 4:1449-1452

23. Wennerberg, K., et al. 2002. RhoG signals in parallel with Rac1 and Cdc42. J. Biol. Chem. 277:47810-47817

24. McLemore, E.C., et al. 2004. Transducible recombinant small heat shock-related protein, HSP20, inhibits vasospasm and platelet aggregation. Surgery.
136:573-578.

25. Kwon, Y.D., et al. 2005. Cellular manipulation of human embryonic stem cells by TAT-PDX1 protein transduction. Mol. Ther. 12:28-32.

26. Merilainen, O., et al. 2005. HIV-1 TAT protein transduction domain mediates enhancement of enzyme prodrug cancer gene therapy in vitro: a study with TAT-TK-GFP triple fusion construct. Int. J. Oncol. 27:203-208.

27. Dietz, G.P., and Bahr, M. 2004. Delivery of bioactive molecules into the cell: the Trojan horse approach. Mol. Cell. Neurosci. 27:85-131.

28. Falnes, P.O., Wesche, J., and Olsens, S. 2001. Ability of the Tat basic domain and VP22 to mediate cell binding but not membrane translocation of the diphtheria toxin A-fragment. Biochemistry. 40:4349-4358.

29. Leifert, J.A., Harkins, S., and Whitton, J.L. 2002. Full-length proteins attached to the HIV tat protein transduction domain are neither transduced between cells, nor exhibit enhanced immunogenicity. Gene Ther. 9:1422-1428.

30. Kaneto, H., et al. 2004. Possible novel therapy for diabetes with cell-permeable JNK-inhibitory peptide. Nat. Med. 10:1128-1132.

31. Noguchi, H., et al. 2004. A new cell-permeable peptide allows successful allogeneic islet transplantation in mice. Nat. Med. 10:305-310.

32. Hosotani, R., et al. 2002. Trojan p16 peptide suppresses pancreatic cancer growth and prolongs survival in mice. Clin. Cancer Res. 8:1271-1276.

33. Flora, G., et al. 2003. Methamphetamine potentiates HIV-1 Tat protein-mediated activation of redox-sensitive pathways in discrete regions of the brain. Exp. Neurol. 179:60-70.

34. Partidos, C.D., et al. 2004. A synthetic HIV-1 Tat protein breaches the skin barrier and elicits Tatneutralizing antibodies and cellular immunity. Eur. J. Immunol. 34:3723-3731.

35. Cui, Z., et al. 2004. Strong T cell type-1 immune responses to HIV-1 Tat (1-72) protein-coated nanoparticles. Vaccine. 22:2631-2640.

36. Lainka, E., et al. 2005. Polyethylene glycol-conjugated adenosine deaminase (ADA) therapy provides temporary immune reconstitution to a child with delayed-onset ADA deficiency. Clin. Diagn. Lab. Immunol. 12:861-866.

37. Carcao, M., et al. 2006. Rituximab for congenital haemophiliacs with inhibitors: a Canadian experience. Haemophilia. 12:7-18.

38. Becker-Hapak, M., McAllister, S.S., and Dowdy, S.F. 2001. TAT-mediated protein transduction into mammalian cells. Methods. 24:247-256

39. Blackburn, M.R., et al. 2000. The use of enzyme therapy to regulate the metabolic and phenotypic consequences of adenosine deaminase deficiency in mice. Differential impact on pulmonary and immunologic abnormalities. J. Biol. Chem. 275:32114-32121.

40. Dalal, I., Grunebaum, E., Cohen, A., and Roifman, C.M. 2001. Two novel mutations in a purine nucleoside phosphorylase (PNP)-deficient patient. Clin. Genet. 59:430-437.

41. Auiti, A., et al. 2002. Correction of ADA-SCID by stem cell gene therapy combined with nonmyeloablative conditioning. Science. 296:2410-2413.
42. Rubio, R., and Berne, R.M. 1980. Localization of purine and pyrimidine nucleoside phosphorylases in heart, kidney, and liver. Am. J. Physiol. 239:H721-H730.

43. Cao, G., et al. 2002. In vivo delivery of a Bcl-xL fusion protein containing the TAT protein trasnduction domain protects against ischemic brain injury and neuronal apoptosis. J. Neurosci. 22:5423-5431.

44. Dietz, G.P., Kilic, E., and Bahr, M. 2002. Inhibition of neuronal apoptosis in vitro and in vivo using TATmediated protein transduction. Mol. Cell. Neurosci. 21:29-37.

45. Cai, S.R., et al. 2006. The kinetics and tissue distribution of protein transduction in mice. Eur. J. Pharm. Sci. 27:311-319.

46. Brooks, H., Lebleu, B., and Vives, E. 2005. Tat peptide-mediated cellular delivery: back to basics. Adv. Drug Deliv. Rev. 57:559-577.

47. Hershfield, M.S., et al. 1991. Use of site-directed mutagenesis to enhance the epitope-shielding effect of covalent modification of proteins with polyethylene glycol. Proc. Natl. Acad. Sci. U. S. A. 88:7185-7189.

48. Bennet, E.M., Li, C., Allen, P.W., Parker, W.B., and Ealick, S.E. 2003. Structural basis for substrate specificity of Escherichia coli purine nucleoside phosphorylase. J. Biol. Chem. 278:47110-47118.

49. Buckley, R.H., et al. 1999. Hematopoietic stem-cell transplantation for the treatment of severe combined immunodeficiency. N. Engl. J. Med. 340:508-516.

50. Sarzotti, M., et al. 2003. T cell repertoire development in humans with SCID after nonablative allogeneic marrow transplantation. J. Immunol. 170:2711-2718

51. Aiuti,A., et al. 2003. Gene therapy for adenosine deaminase deficiency. Curr. Opin. Allergy Clin. Immunol. 3:461-466.

52. Chan, B., et al. 2005. Long-term efficacy of enzyme replacement therapy for adenosine deaminase (ADA)-deficient severe combined immunodeficiency (SCID). Clin. Immunol. 117:133-143.

53. Malacarne, F., et al. 2005. Reduced thymic output, increased spontaneous apoptosis and oligoclonal B cells in polyethylene glycol-adenosine deaminasetreated patients. Eur. J. Immunol. 35:3376-3386.

54. Wraith,J.E. 2006. Limitations of enzyme replacement therapy: Current and future. J. Inherit. Metab. Dis. 29:442-447.

55. Gaspar, J., Gerritsen, B., and Jones, A. 1998. Immunoglobulin replacement treatment by rapid subcutaneous infusion. Arch. Dis. Child. 79:48-51.

56. Peng, L., et al. 2005. Nucleoside transporter expression and function in cultured mouse astrocytes. Glia. 52:25-35.

57. Borsello, T., et al. 2003. A peptide inhibitor of c-Jun $\mathrm{N}$-terminal kinase protects against excitotoxicity and cerebral ischemia. Nat. Med. 9:1180-1186.

58. Jinnah, H.A., et al. 2006. Delineation of the motor disorder of Lesch-Nyhan disease. Brain. 129:1201-1217.

59. Lee, K.O., et al. 2005. Improved intracellular delivery of glucocerebrosidase mediated by the HIV-1 TAT protein transduction domain. Biochem. Biophys. Res. Commun. 337:701-707. 